\title{
Non-classical Celiac Disease: Often Missed
}

\author{
Prashant Singh" ${ }^{1}$, Govind K Makharia ${ }^{2, *}$ \\ ${ }^{1}$ Massachusetts General Hospital, Boston, USA \\ ${ }^{2}$ Department of Gastroenterology and Human Nutrition, All India Institute of Medical Sciences, Ansari nagar, New Delhi, India \\ *Corresponding author: govindmakharia@gmail.com, govindmakharia@aiims.ac.in
}

Received September 01, 2014; Revised September 10, 2014; Accepted September 13, 2014

\begin{abstract}
Celiac disease (CeD) is an immune-mediated enteropathy triggered by ingestion of gluten in genetically susceptible individuals. $\mathrm{CeD}$ is a global disease and estimated to affect approximately one percent of the global population. With advent of simple serological tests for the diagnosis, the number of individuals diagnosed with CeD is increasing exponentially. It was initially thought that gluten hypersensitivity in $\mathrm{CeD}$ is limited to small intestine only and all other features are secondary to malabsorption, but it is now recognized that the hypersensitivity to gluten is not limited to small intestine alone and may affect other organs such as skin, brain, and bones independent of intestinal involvement. $\mathrm{CeD}$ is now considered a multi-system disorder and their clinical presentation may be with gastrointestinal symptoms, called "classical CeD" or more often with non-gastrointestinal symptoms called "nonclassical CeD". These patients may present with short stature, anemia, liver dysfunction (asymptomatic increase in transaminases, chronic liver disease, autoimmune hepatitis), cutaneous manifestations (dermatitis herpetiformis, oral ulcers), reproductive diseases (infertility, recurrent abortions), neurological manifestations (ataxia, peripheral neuropathy), and metabolic disorders (osteopenia/osteoporosis). What determines these variable phenotypes remain unclear but likely is a result of genetic as well as environmental factors. Many of these patients with non-classical $\mathrm{CeD}$ are likely to report to specialists other than gastroenterologists such as hematologists, endocrinologists, rheumatologists or gynecologists. Unfortunately, the awareness about non-classical presentations of CeD amongst health care professionals remains low. There is an urgent need to increase awareness among health care professionals about varied manifestations of $\mathrm{CeD}$ in order to decrease the burden of undiagnosed CeD.
\end{abstract}

Keywords: short stature, anemia, autoimmune hepatitis, gluten ataxia, dermatitis herpatiformis, atypical celiac disease, cirrhosis of liver

Cite This Article: Prashant Singh, and Govind K Makharia, "Non-classical Celiac Disease: Often Missed.” International Journal of Celiac Disease, vol. 2, no. 3 (2014): 76-85. doi: 10.12691/ijcd-2-3-8.

\section{Introduction}

Celiac disease (CeD) is a chronic small intestinal immune-mediated enteropathy triggered by ingestion of a complex protein, gluten, present in cereals such as wheat barley and rye in genetically predisposed individuals. [1] Gluten undergoes deamidation by tissue transglutaminase (tTG) in small intestinal mucosa which allows it to bind to human leukocyte antigen (HLA)-DQ2 and -DQ8, subsequently triggering an inflammatory cascade leading to small intestinal mucosal damage, a hallmark of CeD [1].

It was initially thought that gluten hypersensitivity in CeD is limited to the small intestine only and all other features are secondary to malabsorption, but it is now recognized that many of the features of $\mathrm{CeD}$ may not be explained on the basis of malabsorption alone. [2,3,4,5] It is now recognized that the hypersensitivity to gluten is not limited to the small intestine alone and may affect other organs such as skin, brain, and bones independent of intestinal involvement. [2,3,4,5] Many patients with dermatitis herpetiformis and gluten ataxia for example have normal intestinal mucosal histology. [2,3] Since our knowledge about this disease has grown over the last few decades, CeD is now considered a multi-system disorder and therefore can have varieties of clinical manifestations including both gastrointestinal and non-gastrointestinal.

$\mathrm{CeD}$ was once considered to be a disease of children and cared mainly by pediatricians and not many adult patients were diagnosed to have CeD. Furthermore the spectrum of phenotypic expression of $\mathrm{CeD}$ is very wide and extends from completely asymptomatic to severely symptomatic disease. [1] While some patients have fully expressed disease, in others the disease is expressed in milder form. [1] In some, the disease manifests clinically in early childhood, while in others disease becomes apparent at a later age. [6,7] Furthermore, there are also circumstances when the clinical expression of disease is abrupt and explosive in a relatively asymptomatic individual, which partly may be due to either occurrence of a second hit or development of a complication.

\section{Why There is so much Variation in the Expression of CeD?}

While CeD occurs due to gluten peptide induced both acquired and innate immune response in a genetically susceptible individual; what decides the clinical 
phenotypic expression is not well known. [8] One of the well-known factors which affect the clinical expression of the disease is HLA-DQ2 or -DQ8 homozygosity. [9,10,11,12] Other factors which may have affect on the clinical expression of the disease include time of exposure to gluten, and the amount of gluten ingestion. [13,14] While presence of HLA-haplotype explains approximately 40\% of risk conferred, there is a strong likelihood of other genetic factors playing a role in the expression of the disease. [15] Based on the available evidences, it has been hypothesized that $\mathrm{CeD}$ is a multi-genetic disease and clinical expression of the disease is decided by a combination of major genes and minor genes, once they already have susceptible HLA- haplotype and are exposed to gluten, the last two being the essential factors.

With widespread availability of serological tests, less cumbersome diagnostic criteria and increasing awareness, $\mathrm{CeD}$ is being increasingly diagnosed in patients presenting with both gastrointestinal (Classical) and nongastrointestinal (non-classical) symptoms. [16] $\mathrm{CeD}$ is now considered a multi-system disorder and their clinical presentation may be with gastrointestinal symptoms, called "classical CeD" or more often with nongastrointestinal symptoms called "non-classical CeD”. An expert panel has recently provided some of the relevant clinical terminologies related with $\mathrm{CeD}$ which can should be used in clinical and research settings [1].

Classic or typical $\mathrm{CeD}$ is defined as gluten induced enteropathy presenting with signs/symptoms of malabsorption (such as diarrhea or malnutrition) or a malabsorption syndrome (indicated by weight loss, steatorrhea, vitamin deficiencies and hypoalbuminemia). [1] Atypical or non-classic $\mathrm{CeD}$ is defined as gluten induced enteropathy presenting with signs/symptoms other than those mentioned above. [1] These patients may present with short stature, anemia, liver dysfunction (asymptomatic increase in transaminases, chronic liver disease, autoimmune hepatitis), cutaneous manifestations (dermatitis herpetiformis, oral ulcers), reproductive diseases (infertility, recurrent abortions), neurological manifestations (ataxia, peripheral neuropathy), and metabolic disorders (osteopenia/osteoporosis). [1,6,17] In addition, they could also present with gastrointestinal symptoms, which are not included in classical CeD presentation such as constipation, dyspepsia, or irritable bowel syndrome. [1] Fatigue may be one of the manifestations of CeD [18,19].

The proportion of patients with $\mathrm{CeD}$ who have been diagnosed in comparison to those who still remain undiagnosed is high in certain European countries such as Italy and Finland; while in other countries including United States this proportion is still lower. [20,21] It is predicted that upto $83 \%-95 \%$ of patients with $\mathrm{CeD}$ in the United States still remains undiagnosed. [22,23,24,25] In a cohort of 13,971 children from UK, using anti-endomysial antibody serology, 140 children were expected to have $\mathrm{CeD}$, while only 12 children were diagnosed with $\mathrm{CeD}$ by age of 14 years suggesting that more than $90 \%$ of children with $\mathrm{CeD}$ were not diagnosed. [26] These studies suggest that the diagnosis of $\mathrm{CeD}$ is still not considered even in countries having excellent healthcare services. A part of this could be due to under-recognition of atypical forms of CeD. [26] In this review, we have highlighted some of the non-classical manifestations of $\mathrm{CeD}$, which often are missed and the reasons of why are they missed.

\section{Hematological Manifestations}

Anemia is present in $12 \%$ to $69 \%$ of patients with $\mathrm{CeD}$ in western countries and $85 \%-90 \%$ of patients with CeD in India. [27,28,29,30] Iron deficiency is the commonest cause of anemia in CeD. [27,28] Several studies from North America, Europe and India have suggested that iron deficiency could be the sole manifestation of $\mathrm{CeD}$ even in the absence of diarrhea in them. [31,32,33,34,35] In addition, $8 \%$ to $41 \%$ of patients with $\mathrm{CeD}$ have vitamin $\mathrm{B}_{12}$ deficiency at the time of diagnosis. [30,36,37] The exact reason for deficiency of vitamin B12 is not known, it however may be due to under-secretion of gastric acid, bacterial overgrowth, and occurrence of co-existent autoimmune gastritis. Folate deficiency has also been reported in patients with $\mathrm{CeD}$. [30,38] Anemia in patients with $\mathrm{CeD}$ has been shown to respond very well to gluten free diet (GFD) and iron/vitamin supplementation [28,30].

Conversely, approximately $5-10 \%$ of patients with chronic anemia are found to have $\mathrm{CeD}$ as a cause of anaemia. [33,34,38] Many of them are investigated extensively and referred as refractory anaemia before a diagnosis of $\mathrm{CeD}$ is made in them. The abovementioned observations suggest that $\mathrm{CeD}$ as a cause of anemia in clinical practice is still under-recognized and underinvestigated [33].

Which patients with anemia should be screened for $\mathrm{CeD}$ in a resource limited setting? In developing countries such as India where anemia is far more common than developed countries; it may not be feasible to screen every anemic person for CeD. In a study from India, younger age of onset, longer duration of disease and presence of diarrhea were found to be independent predictors of $\mathrm{CeD}$ in patients presenting with anemia. [34] Furthermore all patients with anemia refractory to iron supplementation should also be screened for CeD [30,34].

Recent evidences suggest that $\mathrm{CeD}$ patients with anemia have significantly longer duration of symptoms, lower albumin levels, higher anti-tTG levels, and higher proportion have abnormal d xylose tests and severe villous atrophy in comparison to $\mathrm{CeD}$ patients having normal hemoglobin. [29] Thus presence of anemia in a patients with CeD denote advanced enteropathy.

It is also important to note that upto $15 \%-35 \%$ of patients with CeD do not have anemia. [28,29] Why some patients with $\mathrm{CeD}$ do not have anemia? Absorptive functions of the intestine are maintained till the intestinal mucosal damage is far advanced. In addition, human body has a large reserve of iron, folate and Vitamin $B_{12}$. [29] Anemia develops only when these reserves are depleted significantly. CeD should thus be considered even in patients with normal hemoglobin levels if there are other features to suspect a diagnosis [29].

The hematological manifestations of $\mathrm{CeD}$ are not limited to anemia but other cell lines and coagulation cascade is also affected. [30] $\mathrm{Up}$ to $60 \%$ of $\mathrm{CeD}$ patients can have thrombocytosis but only a minority of patients have thrombocytopenia. [30] Thrombocytosis is believed to occur due to presence of an active inflammatory state, iron deficiency state and hyposplenism. [30] Folate and 
copper deficiencies can lead to leucopenia in a minority of patients with CeD [30].

Venous thromboembolism has been well reported in $\mathrm{CeD}$ and could be presenting manifestation as in several cases presenting with Budd-Chiari syndrome. [30,39,40] It is believed to be multi-factorial such as hyperhomocystenemia, deficiencies of Vitamin $\mathrm{K}$ dependent anti-coagulant proteins and increased levels of pro-coagulant proteins like thrombin activable fibrinolysis inhibitors. [30] On the other hand, patients with CeD might also have increased bleeding tendencies secondary to deficiencies of vitamin K dependent coagulation factors. [30] A recent study found that $18.5 \%$ of untreated $\mathrm{CeD}$ patients had prolongation of prothrombin time and these patients were also more likely to present with anemia and abnormal iron proteins [41].

\section{Endocrinological Manifestations}

Failure to gain height is a concern both for children as well as their parents. For past one decade, CeD is being increasingly recognized as an important cause of short stature all across the world. The prevalence of $\mathrm{CeD}$ in patients with short stature varies widely from $4.7 \%$ to $15.2 \%$ in various countries. $[42,43,44,45,46]$ The prevalence of $\mathrm{CeD}$ in patients with idiopathic short stature is even higher and ranges from $21 \%$ to $48.7 \%$. [42,47,48,49] Unlike many of the other causes of short stature such as genetic and familial short stature, which do not respond to specific therapeutic intervention; the growth velocity improves in children with $\mathrm{CeD}$ with institution of GFD. [45,46] A negative correlation has been shown between height at the end of 4 years of follow up and age of diagnosis of CeD. [50] A complete catch-up in height has been reported if $\mathrm{CeD}$ is diagnosed early. [46,51,52] It is therefore extremely important to make an early diagnosis to prevent the loss of opportunity to gain age specific height velocity.

Which patients with short stature should be screened for CeD? Patients with anemia and diarrhea have increased odds of having $\mathrm{CeD}$ as cause for failure to thrive. Studies have shown that a significant proportion of short stature patients with $\mathrm{CeD}$ may not have either anemia or diarrhea. [44] In a cohort of Indian children with short stature, 30\% and $12 \%$ children with $\mathrm{CeD}$ did not have diarrhea and anemia, respectively. [43] Therefore, all the patients with short stature should be screened for CeD irrespective of presence of gastrointestinal or hematological manifestations. In view of high prevalence of $\mathrm{CeD}$ among short stature patients and low cost of celiac serological tests, celiac serological test should be included as a first line investigation in the diagnostic algorithm of short stature.

The pathogenesis of short stature in patients with CeD is not very well defined and appears to be multi-factorial. Earlier it was thought that CeD related malnutrition was the only factor responsible for short stature in these patients. There are now evidences that suggest that not all patients with $\mathrm{CeD}$ have gastrointestinal manifestations and/or malnutrition. Patients with $\mathrm{CeD}$ have been reported to have lower levels of both basal and hypoglycemia induced growth hormone levels, lower levels of insulin like growth factor (IGF)-1, IGF-2, insulin like growth factor binding protein (IGFBP)-1 and IGFBP-3. [45,46,53] Additionally, these patients might have partial insensitivity to the growth hormone. Surprisingly, introduction of GFD normalizes many imbalances in the somatotropic axis in the form of increased growth hormone sensitivity and also increased IGF-1, IGF-2 and IGFBP-1. [46,53] Concomitant hypothyroidism, hypogonadism and Turner's syndrome in these patients may also contribute to occurrence of short stature in them [46].

Association between CeD and type 1 diabetes (T1DM) and autoimmune thyroiditis is also well established. Upto $3-12 \%$ of T1DM patients have been reported to have CeD and $1.5-7.4 \%$ of patients with CeD have T1DM [54,55].

Similarly, as many as $10 \%-15 \%$ of patients with CeD have co-existent clinical hypothyroidism or hyperthyroidism and conversely upto $2-4 \%$ of patients with autoimmune thyroid disorders have CeD. [55] The evidences of association between other endocrinopathies such as Addison's disease, primary or secondary hyperparathyroidism, and autoimmune hypophysitis and CeD is not well established [55].

In summary, many of the patients with CeD may have endocrinopathy as the prime manifestation and therefore endocrinologists should consider $\mathrm{CeD}$ as a diagnostic possibility in patients with short stature, autoimmune thyroid disease and TIDM.

\section{Liver Diseases}

Spectrum of liver involvement in CeD ranges from asymptomatic elevation of serum transaminases to end stage liver disease. Elevated serum transaminases have been reported in $24 \%-54 \%$ of patients with CeD. [6,56,57] Conversely, upto $9 \%$ of the patients with chronic unexplained increase in transaminases have been reported to have CeD.[58] The response to GFD is excellent in more than two thirds of patients, the transaminases in them normalize within 6 months to one year [56,57].

$\mathrm{CeD}$ has also been reported to co-exist with other autoimmune liver diseases such as autoimmune hepatitis, primary biliary cirrhosis and primary sclerosing cholangitis. Four to $6 \%$ of patients with autoimmune hepatitis are reported to have CeD. [57,59,60] Van-Gerven, et al in a recent study including 410 patients with autoimmune hepatitis reported 3.5\% of them having seropositive for $\mathrm{CeD}$ which was higher than the $0.35 \%$ prevalence of $\mathrm{CeD}$ in the general Dutch population. [61] Similarly, $4 \%-11 \%$ of patients with primary biliary cirrhosis have co-existent CeD. [57] Large population based cohorts from Sweden and Denmark have reported a standardized incidence ratio of 25-28 for primary biliary cirrhosis in patients with CeD. [62] Conversely, patients with $\mathrm{CeD}$ have more than three times increased odds of having primary biliary cirrhosis compared to the occurrence of primary biliary cirrhosis in the general population $(0.17 \%$ vs $0.05 \%)$. [63] In another large population based cohort of $13,818 \mathrm{CeD}$ patients, Ludvigsson et al have reported 4.5 times increased risk of having primary sclerosing cholangitis amongst patients with $\mathrm{CeD}$ in comparison to that in the general population. [64] In patients having a combination of both autoimmune liver disorders and $\mathrm{CeD}$, symptoms of one might precede the other, or even may co-exist at the time of diagnosis and therefore need careful evaluation [65]. 
There are several levels of evidences, such as clinical observations, case series and population based cohort studies suggesting an association between $\mathrm{CeD}$ with chronic liver disease (CLD) or cirrhosis. [40,64,66,67] Patients with CeD are also more likely to die from liver cirrhosis than the general population. [67] Kaukinen, et al had reported reversal of hepatic dysfunction after initiation of gluten free diet (GFD) in four patients awaiting liver transplantation and eventually three of them were remitted from liver transplantation list. Furthermore, CeD was detected in 8 (4.3\%) of 185 patients who underwent liver transplantation previously and later screened for CeD. [68] In a more recent prospective study, Wakim-Fleming et al reported CeD in 2.5\% of 204 consecutive biopsy proven patients with liver cirrhosis. [66] They also reported improvement in liver function tests with initiation of GFD in these patients. [66] Based on the abovementioned study, in can be concluded that the prevalence of $\mathrm{CeD}$ in patients with cirrhosis is more than two times than that in the general population.

Which are the patients with chronic liver disease who should be investigated for presence of concomitant CeD? The reasons for suspicion of $\mathrm{CeD}$ in patients with cirrhosis generally are presence of chronic diarrhea, short stature and disproportionately severe anemia or iron refractory anemia in them. [40,65] Chronic diarrhea in cirrhosis might be attributed to bacterial overgrowth and intestinal mucosal edema. Similarly, anemia in cirrhotic patients could be caused by GI bleeding, hypersplenism and anemia of chronic disease. If liver disease sets in early years of life, it could itself lead to growth retardation. Therefore, most of these manifestations pointing towards presence of $\mathrm{CeD}$ can well be explained by cirrhosis itself and thus alternative causes for these manifestations may not be considered in a patient with cirrhosis. Because of overlapping manifestations of cirrhosis and $\mathrm{CeD}$, there is a likelihood of missing the diagnosis of $\mathrm{CeD}$ if the main presentation of $\mathrm{CeD}$ is like cirrhosis unless actively considered.

The abovementioned evidences while suggest an association between $\mathrm{CeD}$ and spectrum of liver diseases, morphological changes that occur in the liver however is not well known except for a study by Jabobson, et al. Jacobsen, et al have reported histological changes in the liver of 37 patients with $\mathrm{CeD}$ having increase in serum transaminases. [69] Of 37 of these patients, 5 had normal liver on histological examination, 25 had nonspecific necro-inflammatory changes in the liver, 6 had chronic hepatitis, and one had primary sclerosing cholangitis [69].

How CeD leads to liver dysfunction is also not known. While population-based studies support an association between autoimmune hepatitis, primary sclerosing cholangitis and primary biliary cirrhosis with $\mathrm{CeD}$, the exact reasons of association are not well established. While it is well known that patient having one autoimmune disease can have another autoimmune disease; therefore mere presence of two autoimmune diseases in an individual do not confirm causality. At present, there is no tissue specific marker/staining/cellular repertoire to support liver damage caused by gluten. $\mathrm{CeD}$ and autoimmune hepatitis are both associated with specific class II HLA molecules encoding for HLA complex genes on chromosome 6. [56,57] Novacek, however, reported significantly higher intestinal permeability in patients with
CeD who had elevated serum transaminases compared with those with normal serum transaminases. [70] Tansglutaminase-2 which is central pathogenesis of $\mathrm{CeD}$, has also been shown to modulate inflammation and fibrosis in chronic liver disease. [71] One of the valid requirements for establishing the association between autoimmune diseases and $\mathrm{CeD}$ is to demonstrate reversibility of the liver damage by GFD. Further studies are needed to better delineate the pathogenesis of liver involvement in $\mathrm{CeD}$. Also, long term follow-up and paired liver biopsies in patients with coexistent $\mathrm{CeD}$ and liver disease, while being on strict GFD, would help in delineating the mechanisms of liver damage in patients with CeD.

\section{Bone and Metabolic Disease}

\subsection{Osteoporosis and Osteopenia in Patients with CeD}

CeD predisposes individuals of all age to low bone mineral density (BMD). Twenty six percent to $74 \%$ of adult patients with $\mathrm{CeD}$ have osteopenia or osteoporosis. [72,73,74,75] Similarly, children and adolescents with $\mathrm{CeD}$ have been found to have lower BMD in comparison to healthy children. [76] In a prospective study, Margoni, et al reported that approximately $30 \%$ of children with $\mathrm{CeD}$ had BMD below 2.5 ${ }^{\text {th }}$ percentile of the normal population at the time of diagnosis. Furthermore, the BMD $\mathrm{z}$ scores continued to be significantly lower than that in the general population even upto 2 years after institution of GFD [77].

\subsection{CeD in Patients with Osteopenia and Osteoporosis}

Conversely, 0-3.4\% patients having low BMD have been found to have CeD. [78] Patients with osteomalacia and proximal myopathy both in developing as well as developed nations are also reported to have $\mathrm{CeD}[78,79]$.

While a few population-based cohort studies suggest that patients with $\mathrm{CeD}$ are not at a higher risk for fractures; another population-based large Danish cohort study has shown a higher risk of hip fracture (hazard ratio $=1.4$ ) in them.[80-84] In a general population-based cohort study that included individuals with $\mathrm{CeD}(n=14,187)$ and reference individuals $(n=14,187)$, CeD was positively associated with subsequent hip fracture (hazard ratio [HR], 2.1; 95\% confidence interval [CI], 1.8-2.4) and fractures of any type (HR 1.4; 95\% CI 1.3-1.5). [84] A systematic review with a meta-analysis, that pooled 20,995 CeD patients and 97,777 controls from eight studies published between 2000 and 2007, indicated that CeD patients have a $43 \%$ higher risk for fracture compared with subjects without CeD [85].

Children with $\mathrm{CeD}$ can attain normal peak bone mass if the diagnosis is made early and GFD is started before puberty. While some studies have shown that BMD return to normal after one year of GFD in children diagnosed with $\mathrm{CeD}$, others have failed to show complete normalization by this time. [77,86,87] Similarly, GFD is considered the most rational approach for osteoporosis/ osteopenia in adult patients with CeD. Nevertheless, a 
GFD rarely normalizes BMD in adulthood. [88] A recent study has shown that despite long-term strict adherence to GFD, $74 \%$ of them still had low BMD, and $24 \%$ of them having even osteoporosis. [76] Therefore, calcium and vitamin D supplementation should be considered for adult patients with CeD.

The pathophysiology of bone loss in patients with CeD is multifactorial; the two main mechanisms being malabsorption of calcium and vitamin $\mathrm{D}$ and release of pro-inflammatory cytokines leading to osteoclast activation.[76,88] Calcium malabsorption in CeD induces increase in parathyroid hormone secretion, which in turn, increases bone turnover and cortical bone loss.

\section{Neurological Manifestations}

In recent years, $\mathrm{CeD}$ has been associated with neurological and psychiatric disorders including peripheral neuropathy, epilepsy, dementia, cerebellar ataxia and depression. If looked carefully, approximately $23 \%-50 \%$ of patients with $\mathrm{CeD}$ have signs/symptoms of peripheral neuropathy. [89,90,91] In a large populationbased registry from Sweden including 14,000 patients with $\mathrm{CeD}$ and 70,000 controls, Ludvigsson reported three fold higher risk of developing polyneuropathy. [92] Neuropathy in CeD generally is distal symmetric sensory neuropathy but they might also have pure motor neuropathy, mono-neuritis multiplex and autonomic neuropathy. [93] In addition, an unique terminology 'gluten related neuropathy' has been coined for individuals with otherwise sporadic peripheral neuropathy and having serologic (a positive AGA or anti-tTG Ab or AEA) evidence of gluten related disorders. [94,95] 'Gluten related neuropathy' is a slowly progressive disease occurring in people around 55 years of age. Villous enteropathy have been described in one-third of these patients. [94] While some investigators have reported improvement in neuropathic symptoms with GFD, others have failed to show any such response. $[89,96]$ However, in a systematic study by Hadjivassiliou et al, improvement was found in sural nerve sensory action potential along with subjective improvement in neuropathic symptoms in 35 patients with gluten neuropathy, who maintained a strict GFD for atleast 1 year. Recovery remains incomplete in patients with more severe disease, thereby suggesting the importance of detecting the disease early in its course [94].

Cerebellar ataxia is another common manifestation of $\mathrm{CeD}$ and has been shown to be present in upto $6 \%$ of patients with biopsy proven CeD. [97] In a study by Hadijivassiliou et al, upto $41 \%$ of patients with sporadic cerebellar ataxia (54/132) were attributed to gluten ataxia. [98] One fourth of these patients with gluten ataxia were found to have $\mathrm{CeD}$ on the duodenal biopsy. In another study, 12 of 104 (11.5\%) patients with idiopathic ataxia and negative genetic testing were reported to have a positive serological marker for CeD (AGA/AEA) in comparison to 5\% of 600 healthy blood donors. [99] They also reported strong association between a positive serology and HLA-genotypes linked with CeD, suggesting gluten ataxia being a part of the gluten related disorders. [99] Gluten ataxia is now defined as presence of otherwise idiopathic sporadic ataxia in association with positive anti- gliadin antibodies (IgG or IgA or both) with or without enteropathy on the duodenal biopsy. [1] Anti-tTG-6 antibody is now being identified as a potential new serological marker for gluten ataxia. [100] Upto 60\% of patients with gluten ataxia have MRI evidence of cerebellar atrophy. [95] There are now evidences that ataxia improves with initiation of GFD in such patients. Only available systematic study have reported improvement in ataxia (improvement in ataxia tests) after one year in 46 patients with gluten ataxia who strictly adhered to GFD compared to those 14 patients who refused to follow GFD. The improvement in ataxia was noticed even when these patients did not have enteropathy [101].

'Gluten encephalopathy' is a term used to describe individuals with gluten related disorder having headache and white matter changes on MRI. [95] Gluten encephalopathy may not always occur in isolation and may co-existent with other gluten-related neurological conditions. Additionally, $4.3 \%$ of patients with migraine have been reported to have $\mathrm{CeD}$, which is higher than the prevalence of CeD in the general population. [102] Other less common neurological manifestations of gluten related disorders are myopathy, myelopathy, epilepsy, dementia, cognitive impairment and depression [95].

The neurological manifestations in gluten related disorders may occur because of two main reasons; malabsorption of vitamin specifically vitamin $\mathrm{B}_{1}, \mathrm{~B}_{6}, \mathrm{~B}_{12}$ and $\mathrm{E}$ deficiencies and neurological sensitivity to gluten.[93] Furthermore, it remains unclear whether these antibodies (including anti-tTG 6) are neurotoxic or are representative of an epiphenomenon [93].

\section{Mucocutaneous Manifestations}

Dermatitis herpetiformis (DH) is a cutaneous manifestation of small intestinal immune mediated enteropathy precipitated by exposure to dietary gluten. [1] It is characterized by clusters of pruritic papules and vesicles associated with intense pruritus, which are followed by erosions and excoriations. The typical sites for DH lesions include extensor surfaces of upper and lower extremities, elbows, knees, scalp and buttocks [103].

Skin biopsy is needed for the diagnosis. During initial phase the skin biopsies show, edema in the papillary dermis and neutrophilic infiltration along the dermalepidermal junction. As the lesions progress, along with neutrophils, eosinophils and fibrin accumulate along dermal papillae and form micro-abscesses. On direct immunofluorescence, granular IgA deposition is seen in the dermal papillae and/or along the basement membrane and they are considered as gold standard for the diagnosis of DH. [103,104,105] Majority of these patients also have intestinal villous atrophy in patients with DH [1].

GFD is the first line of therapy for DH similar to that for CeD. [1] It takes several months before skin lesions start improving. Other drugs such as dapsone, sulfasalazine, topical potent corticosteroids and antihistaminics should be used as symptomatic agents. [103,106] Among these, dapsone is the best tolerated and most widely used pharmacologic therapy for $\mathrm{DH}$ in both adults and children. [103] While the cutaneous lesions improve and become less pruritic with use of dapsone, the 
lesions however reappear on discontinuation of dapsone. This is because daspone suppresses the inflammation in the skin but has no influence on the disease process. [103] Till the antigenic challenge is withdrawn, the disease process persists and therefore a GFD is the counterstone of the therapy.

Oral lesions are fairly common in $\mathrm{CeD}$ and include recurrent aphthous ulcerations, glossitis, angular cheilitis and burning in the mouth. [107,108] About 3\%-6\% of patients with oral manifestations may have underlying CeD. [108] Other less common cutaneous manifestations associated with $\mathrm{CeD}$ are psoriasis, urticaria, alopecia areata and necrolytic migratory erythema [108].

\section{Gynecological Manifestations}

CeD has been shown to be present in about $2 \%-3 \%$ of women presenting with infertility which is higher than the prevalence of CeD in the general population. [109,110,111] We recently conducted a meta-analysis and found that women with infertility had 3.5 times higher odds of having duodenal biopsy proven $\mathrm{CeD}$ in comparison to that in the control population (OR 3.5, 95\% CI 1.39 ; $p<.01$ ). [112] In another metaanalysis, Tersigini et al have also shown that females with unexplained infertility have about 5 times increased odds of having CeD [113].

Several studies have also suggested unfavorable pregnancy outcomes in patients with $\mathrm{CeD}$. $\mathrm{CeD}$ has been associated with recurrent abortions, intra-uterine growth retardation, and low birth weight (preterm and small for gestational age). [114,115,116,117] Tesergini et al in their recent meta-analysis also confirmed a significantly increased risk of miscarriage, IUGR, low birth weight and preterm delivery in patients with CeD [113].

These gynecological and obstetric manifestations in patients with CeD could partly be due to micronutrient deficiency particularly zinc, selenium, iron, folate and vitamin $B_{12}$. [113] In-vitro studies have shown that antitTG antibodies in CeD could bind to trophoblastic cells and induce their apoptosis thus leading to placental damage. [113] There is also evidence that anti-tTG antibodies could bind to endometrial endothelial cells and suppress angiogenesis affecting both implantation as well as placenta formation [113].

\section{Why is Non-classical CeD Missed?}

As discussed above, firstly spectrum of CeD is now changing across the world and more than half of $\mathrm{CeD}$ patients now present with non-classical manifestations. $[6,118]$ It is important to realize that almost any of these non-classical manifestations can occur in absence of gastrointestinal symptoms and therefore a high index of suspicion is necessary.

Secondly, patients with non-classical manifestations do not directly present to gastroenterologists. [6] A significant number of $\mathrm{CeD}$ patients now present to hematologists, endocrinologists, gynecologists, neurologists and internists and family physicians because of varied manifestations described above. Despite nonclassical manifestations being common in CeD, awareness about $\mathrm{CeD}$ in health care professionals remains low. In a national survey by Smukalla et al who interviewed 385 hematologists in the USA, only $8.6 \%$ believed that all patients with iron deficiency anemia should be screened for CeD. [119] Physicians who have recently finished their fellowship and those who see a high volume of patients with IDA are more likely to screen for CD. This might have been because of increased awareness of $\mathrm{CeD}$ in this sub-group of physicians [119].

Thirdly, CeD has been believed to be a disease of pediatric population. Studies have shown that $\mathrm{CeD}$ is not only common in adult population but also in elderly. In a recent study from India, 9\% of patients with $\mathrm{CeD}$ were diagnosed after the age of 50 years. It is important to acknowledge that $\mathrm{CeD}$ can occur at any age and should be considered in appropriate clinical settings, irrespective of age [7].

\section{How to Increase Knowledge about CeD}

It is essential that awareness of and knowledge about $\mathrm{CeD}$ and its disease associations increase amongst medical practitioners. The obvious groups to target are pediatricians, family physicians, gastroenterologists and histopathologists. However, it should be emphasized that $\mathrm{CeD}$ may report to other medical specialists such as endocrinologists where patients present with short stature or type I diabetes, to hematologists with anemia, to rheumatologists with metabolic bone diseases, and to gynecologists with delay in menarche, secondary amenorrhea or infertility.

Currently, a due emphasis is not placed on CeD in the undergraduate and postgraduate medical curriculum. In the majority of the undergraduate and postgraduate textbooks of medicine, $\mathrm{CeD}$ is generally dealt with in the chapters on malabsorption and only limited information about CeD is provided. A due emphasis should be put on $\mathrm{CeD}$ during undergraduate and postgraduate medical education. Furthermore, a constant reminder should be provided to physicians, internists, gastroenterologists, hematologists, and endocrinologists through continuing medical education programmes. The first contact of patients with $\mathrm{CeD}$ are generally primary care physicians and family physicians. Empowering primary care physicians and family physicians should play key role in increasing detection of CeD.

\section{How to Investigate?}

All patients with suspected $\mathrm{CeD}$ should be screened using anti-tTG antibodies and/or anti-endomysial antibodies. Recently, point of care test have also been developed which also make it possible to screen for CeD in primary care or resource limited settings. Patients with positive serology should be referred to gastroenterologists for duodenal biopsies to confirm the diagnosis. Once the diagnosis is confirmed, patients should be started on strict and lifelong GFD.

\section{Conclusions}

Many of patients with non-classical CeD are likely to report to specialists other than gastroenterologists such as 
hematologists, endocrinologists, rheumatologists or gynecologists. Unfortunately, the awareness about nonclassical presentations of $\mathrm{CeD}$ amongst health care professionals remains low. There is an urgent need to increase awareness among health care professionals about varied manifestations of $\mathrm{CeD}$ in order to decrease the burden of undiagnosed CeD.

Table: Non-classical manifestations of Celiac disease

\begin{tabular}{|l|l|l|l|l|}
\hline & Symptoms & Prevalence of CeD (\%) & Type of studies & References \\
\hline Hematological manifestations & Anemia & $1.8-8.7 \%$ & Prospective & {$[30,31,32,33,34]$} \\
\hline \multirow{4}{*}{ Endocrinological manifestations } & Short stature & $4.7-15.2 \%$ & Prospective & {$[42,43,44,45,46]$} \\
\cline { 2 - 5 } & Type 1 Diabetes & $3-12 \%$ & Prospective & {$[54,55]$} \\
\cline { 2 - 5 } & Autoimmune thyroiditis & $2-7.8 \%$ & Prospective & {$[55]$} \\
\hline \multirow{5}{*}{ Liver disease } & Unexplained transaminitis & $9 \%$ & Prospective & {$[58]$} \\
\cline { 2 - 5 } & Autoimmune hepatitis & $3.5-6 \%$ & Prospective & {$[59,60,61]$} \\
\cline { 2 - 5 } & Primary biliary cirrhosis & $4-11 \%$ & Prospective & {$[57]$} \\
\cline { 2 - 5 } & Primary sclerosing cholangitis & $1.6 \%$ & Prospective & {$[57]$} \\
\cline { 2 - 5 } & Chronic liver disease & $2.3-4.5 \%$ & Prospective & {$[66,68]$} \\
\hline Bone metabolism & Osteoporosis and osteopenia & $0.8-3.4 \%$ & Prospective & {$[88]$} \\
\hline Neurological manifestations & Sporadic ataxia & Prospective & {$[98,99]$} \\
\hline Gynecological manifestations & Infertility & Prospective & {$[109,110,111]$} \\
\hline
\end{tabular}

\section{References}

[1] Ludvigsson JF, Leffler DA, Bai JC, Biagi F, Fasano A, Green PHR, Hadjivassiliou M, Kaukinen K, Kelly CP, Leonard JN, Lundin KE, Murray JA, Sanders DS, Walker MM, Zingone F, Ciacci C, "The Oslo definitions for coeliac disease and related terms," Gut,62 (1),43-52, Jan 2013.

[2] Hadjivassiliou M, Sanders DS, Grünewald RA, Woodroofe N, Boscolo S, Aeschlimann D, " Gluten sensitivity: from gut to brain," Lancet Neurology, 9 (3), 318-30, Mar 2010.

[3] Antiga E, Caproni M, Pierini I, Bonciani D, Fabbri P, "Gluten-free diet in patients with dermatitis herpetiformis: not only a matter of skin," Arch Dermatol, 147 (8), 988-989, Aug 2011.

[4] Marsh MN, "Gluten, major histocompatibility complex, and the small intestine. A molecular and immunobiologic approach to the spectrum of gluten sensitivity ('celiac sprue')," Gastroenterology, 102(1), 330-54, Jan 1992.

[5] Makharia G, "Where are Indian adult celiacs?," Trop Gastroenterol, 27(1), 1-3, Jan-Mar 2006.

[6] Sharma M, Singh P, Agnihotri A, Das P, Mishra A, Verma AK, Ahuja A, Sreenivas V, Khadgawat R, Gupta SD, Makharia GK, "Celiac disease: a disease with varied manifestations in adults and adolescents," J Dig Dis, 14(10), 518-25, Oct 2013.

[7] Singh P, Shergill S, Makharia GK, "Celiac disease in older adults," J Gastrointest Liver Dis, 22(3), 359-60, Sep 2013.

[8] Schuppan D, Junker Y, Barisani D, "Celiac disease: from pathogenesis to novel therapies," Gastroenterology, 137(6), 191233, Dec 2009.

[9] Karinen H, Kärkkäinen P, Pihlajamäki J, Janatuinen E, Heikkinen M, Julkunen R, Kosma VM, Naukkarinen A, Laakso M, "Gene dose effect of the DQB $1 * 0201$ allele contributes to severity of coeliac disease," Scand J Gastroenterol, 41(2), 191-9, Feb 2006.

[10] Murray JA, Moore SB, Van Dyke CT, Lahr BD, Dierkhising RA, Zinsmeister AR, Melton LJ 3rd, Kroning CM, El-Yousseff M, Czaja AJ, "HLA DQ gene dosage and risk and severity of celiac disease," Clin Gastroenterol Hepatol, 5(12), 1406-12, Dec 2007.

[11] Al-Toma A, Goerres MS, Meijer JWR, Peña AS, Crusius JBA, Mulder CJJ, "Human leukocyte antigen-DQ2 homozygosity and the development of refractory celiac disease and enteropathyassociated T-cell lymphoma," Clin Gastroenterol Hepatol, 4(3), 315-9, Mar 2006.

[12] Biagi F, Bianchi PI, Vattiato C, Marchese A, Trotta L, Badulli C, De Silvestri A, Martinetti M, Corazza GR., "Influence of HLADQ2 and DQ8 on severity in celiac Disease," J Clin Gastroenterol, 46(1): 46-50. Jan 2012.

[13] Ludvigsson JF, Fasano A, "Timing of introduction of gluten and celiac disease risk," Ann Nutr Metab, 60 Suppl 2, 22-9, 2012.
[14] Silano M, Agostoni C, Guandalini S, "Effect of the timing of gluten introduction on the development of celiac disease," World $J$ Gastroenterol, 16(16), 1939-42, Apr 2010.

[15] Hunt KA, van Heel DA, "Recent advances in coeliac disease genetics," Gut, 58(4), 473-6, Apr 2009.

[16] Gadewar S, Fasano A, "Celiac disease: is the atypical really typical? Summary of the recent National Institutes of Health Consensus Conference and latest advances," Curr Gastroenterol Rep, 7(6):455-61, Dec 2005

[17] Green PHR, Cellier C, "Celiac disease," N Engl J Med, 357(17), 1731-43, Oct 2007.

[18] Jordá FC, López Vivancos J, "Fatigue as a determinant of health in patients with celiac disease," J Clin Gastroenterol, 44(6): 423-7, Jul 2010.

[19] Siniscalchi M, Iovino P, Tortora R, Forestiero S, Somma A Capuano L, Franzese MD, Sabbatini F, Ciacci C, "Fatigue in adult coeliac disease," Aliment Pharmacol Ther, 22(5):489-94, Sep 2005.

[20] Catassi C, Fabiani E, Rätsch IM, Coppa GV, Giorgi PL, Pierdomenico R, Alessandrini S, Iwanejko G, Domenici R, Mei E, Miano A, Marani M, Bottaro G, Spina M, Dotti M, Montanelli A, Barbato M, Viola F, Lazzari R, Vallini M, Guariso G, Plebani M, Cataldo F, Traverso G, Ventura A, "The coeliac iceberg in Italy. A multicentre antigliadin antibodies screening for coeliac disease in school-age subjects," Acta Paediatr, Suppl 412: 29-35, May 1996.

[21] Virta LJ, Kaukinen K, Collin P, "Incidence and prevalence of diagnosed coeliac disease in Finland: results of effective case finding in adults," Scand J Gastroenterol, 44(8), 933-8, 2009.

[22] Murray JA, Van Dyke C, Plevak MF, Dierkhising RA, Zinsmeister AR, Melton LJ, "Trends in the identification and clinical features of celiac disease in a North American community, 1950-2001," Clin Gastroenterol Hepatol, 1(1), 19-27, Jan 2003.

[23] Katz KD, Rashtak S, Lahr BD, Melton LJ, Krause PK, Maggi K, Talley NJ, Murray JA, " Screening for celiac disease in a North American population: sequential serology and gastrointestinal symptoms," Am J Gastroenterol, 106(7), 1333-9, Jul 2011.

[24] Catassi C, Kryszak D, Bhatti B, Sturgeon C, Helzlsouer K, Clipp SL, Gelfond D, Puppa E, Sferruzza A, Fasano A, "Natural history of celiac disease autoimmunity in a USA cohort followed since 1974," Ann Med, 42(7), 530-8, Oct 2010.

[25] Rubio-Tapia A, Ludvigsson JF, Brantner TL, Murray JA, Everhart $\mathrm{JE}$, "The prevalence of celiac disease in the United States," Am J Gastroenterol, 107(10), 1538-1544, Oct 2012.

[26] Ravikumara M, Nootigattu VKT, Sandhu BK, "Ninety percent of celiac disease is being missed," J Pediatr Gastroenterol Nutr, 45(4):497-9, Oct 2007.

[27] Bodé S, Gudmand-Høyer E, "Symptoms and haematologic features in consecutive adult coeliac patients," Scand J Gastroenterol, 31(1): 54-60, Jan 1996. 
[28] Harper JW, Holleran SF, Ramakrishnan R, Bhagat G, Green PHR, "Anemia in celiac disease is multifactorial in etiology," $\mathrm{Am} \mathrm{J}$ Hematol, 82 (11): 996-1000, Nov 2007.

[29] Singh P, Arora S, Makharia GK, "Presence of anemia in patients with celiac disease suggests more severe disease," Indian $J$ Gastroenterol, 33(2): 161-4. Mar 2014.

[30] Halfdanarson TR, Litzow MR, Murray JA, "Hematologic manifestations of celiac disease," Blood, 109(2): 412-21, Jan 2007.

[31] Corazza GR, Valentini RA, Andreani ML, D’Anchino M, Leva MT, Ginaldi L, De Feudis L, Quaglino D, Gasbarrini G, "Subclinical coeliac disease is a frequent cause of iron-deficiency anaemia," Scand J Gastroenterol, 30 (2): 153-6, Feb 1995.

[32] Mandal AK, Mehdi I, Munshi SK, Lo TCN, "Value of routine duodenal biopsy in diagnosing coeliac disease in patients with iron deficiency anaemia," Postgrad Med J; 80(946): 475-7, Aug 2004.

[33] Unsworth DJ, Lock RJ, Harvey RF, "Improving the diagnosis of coeliac disease in anaemic women," Br J Haematol, 111(3): 898901, Dec 2000

[34] Kavimandan A, Sharma M, Verma AK, Das P, Mishra P, Sinha S, Mohan A, Sreenivas V, Datta Gupta S, Makharia GK, "Prevalence of celiac disease in nutritional anemia at a tertiary care center," Indian J Gastroenterol, 33 (2): 114-8, Mar 2014.

[35] Varma S, Malhotra P, Kochhar R, Varma N, Kumari S, Jain S, "Celiac disease presenting as iron-deficiency anemia in northern India," Indian J Gastroenterol, 20(6): 234-6, Nov-Dec 2001.

[36] Dahele A, Ghosh S, "Vitamin B12 deficiency in untreated celiac disease," Am J Gastroenterol, 96(3):745-50, Mar 2001.

[37] Haapalahti M, Kulmala P, Karttunen TJ, Paajanen L, Laurila K, Mäki M, Mykkänen $\mathrm{H}$, Kokkonen J, "Nutritional status in adolescents and young adults with screen-detected celiac disease," J Pediatr Gastroenterol Nutr, 40(5): 566-70, May 2005.

[38] Howard MR, Turnbull AJ, Morley P, Hollier P, Webb R, Clarke A, "A prospective study of the prevalence of undiagnosed coeliac disease in laboratory defined iron and folate deficiency," J Clin Pathol, 55 (10): 754-7, Oct 2002.

[39] Afredj N, Metatla S, Faraoun SA, Nani A, Guessab N, Benhalima M, Bendib SE, Debzi N, Layaida K, Gamar L, Baiod N, Balamane M, Kaddache N, Bounab N, Kecili L, Boucekkine T, "Association of Budd-Chiari syndrome and celiac disease," Gastroentérologie Clin Biol, 34 (11): 621-4, Nov 2010.

[40] Singh P, Agnihotri A, Jindal G, Sharma PK, Sharma M, Das P, Gupta D, Makharia GK, "Celiac disease and chronic liver disease: is there a relationship?," Indian J Gastroenterol, 32(6): 404-8, Nov 2013.

[41] Cavallaro R, Iovino P, Castiglione F, Palumbo A, Marino M, Di Bella S, Sabbatini F, Labanca F, Tortora R, Mazzacca G, Ciacci C, "Prevalence and clinical associations of prolonged prothrombin time in adult untreated coeliac disease," Eur J Gastroenterol Hepatol, 16 (2): 219-23, Feb 2004.

[42] Van Rijn JCW, Grote FK, Oostdijk W, Wit JM, "Short stature and the probability of coeliac disease, in the absence of gastrointestinal symptoms," Arch Dis Child, 89 (9): 882-3, Sep 2004.

[43] Bhadada SK, Bhansali A, Kochhar R, Menon AS, Sinha SK, Dutta $\mathrm{P}$, Nain CK, "Does every short stature child need screening for celiac disease?," J Gastroenterol Hepatol, 23(8pt 2): e353-356, Aug 2008.

[44] Queiroz MS, Nery M, Cançado EL, Gianella-Neto D, Liberman B, "Prevalence of celiac disease in Brazilian children of short stature," Braz J Med Biol Res, 37(1): 55-60, Jan 2004.

[45] Meazza C, Pagani S, Laarej K, Cantoni F, Civallero P, Boncimino A, Bozzola M, "Short stature in children with coeliac disease," Pediatr Endocrinol Rev PER; 6 (4): 457-63, June 2009.

[46] Troncone R, Kosova R, "Short stature and catch-up growth in celiac disease," J Pediatr Gastroenterol Nutr, 51 (Suppl 3): S137138, Dec 2010

[47] Groll A, Candy DC, Preece MA, Tanner JM, Harries JT, "Short stature as the primary manifestation of coeliac disease," Lancet;2(8204): 1097-9, Nov 1980.

[48] Bonamico M, Sciré G, Mariani P, Pasquino AM, Triglione P, Scaccia S, Ballati G, Boscherini B, "Short stature as the primary manifestation of monosymptomatic celiac disease," $J$ Pediatr Gastroenterol Nutr,14 (1): 12-6, Jan 1992.

[49] Hashemi J, Hajiani E, Shahbazin H-B, Masjedizadeh R, Ghasemi $\mathrm{N}$, "Prevalence of celiac disease in Iranian children with idiopathic short stature," World J Gastroenterol, 14(48):7376-80, Dec 2008.

[50] Aydogdu S, Midyat L, Cakir M, Tumgor G, Yuksekkaya HA Baran M, Arikan C, Ozgenc F, Yagci RV, "Long-term effect of gluten-free diet on growth velocity in Turkish children with celiac disease," Dig Dis Sci;54 (10): 2183-7, Oct 2009.

[51] Patwari AK, Kapur G, Satyanarayana L, Anand VK, Jain A Gangil A, Balani B, "Catch-up growth in children with latediagnosed coeliac disease," Br J Nutr; 94(3):437-42, Sep 2005.

[52] Damen GM, Boersma B, Wit JM, Heymans HS, "Catch-up growth in 60 children with celiac disease," J Pediatr Gastroenterol Nutr, 19 (4): 394-400, Nov 1994.

[53] Street ME, Volta C, Ziveri MA, Zanacca C, Banchini G, Viani I, Rossi M, Virdis R, Bernasconi S, "Changes and relationships of IGFS and IGFBPS and cytokines in coeliac disease at diagnosis and on gluten-free diet," Clin Endocrinol (Oxf), 68(1): 22-8, Jan 2008.

[54] Husby S, Koletzko S, Korponay-Szabó IR, Mearin ML, Phillips A Shamir R, Troncone R, Giersiepen K, Branski D, Catassi C, Lelgeman M, Mäki M, Ribes-Koninckx C, Ventura A, Zimmer KP ESPGHAN Working Group on Coeliac Disease Diagnosis; ESPGHAN Gastroenterology Committee; European Society forPe diatric Gastroenterology, Hepatology, and Nutrition, "European Society for Pediatric Gastroenterology, Hepatology, and Nutrition guidelines for the diagnosis of coeliac disease," $J$ Pediatr Gastroenterol Nutr, 54: 136-60, 2012

[55] Collin P, Kaukinen K, Välimäki M, Salmi J, "Endocrinological disorders and celiac disease," Endocr Rev, 23(4): 464-83, Aug 2002.

[56] Rostami-Nejad M, Haldane T, Aldulaimi D, Alavian SM, Zali MR Rostami K, "The role of celiac disease in severity of liver disorders and effect of a gluten free diet on diseases improvement," Hepat Mon, 13(10): e11893, Oct 2013.

[57] Rubio-Tapia A, Murray JA, "The liver in celiac disease," Hepatol Baltim Md, 46(5): 1650-8, Nov 2007.

[58] Volta U, De Franceschi L, Lari F, Molinaro N, Zoli M, Bianchi FB," Coeliac disease hidden by cryptogenic hypertransaminasaemia," Lancet, 352(9121): 26-9, July 1998.

[59] Volta U, De Franceschi L, Molinaro N, Cassani F, Muratori L, Lenzi M, Bianchi FB, Czaja AJ, "Frequency and significance of anti-gliadin and anti-endomysial antibodies in autoimmune hepatitis," Dig Dis Sci; 43(10): 2190-5, Oct 1998.

[60] Villalta D, Girolami D, Bidoli E, Bizzaro N, Tampoia M, Liguori M, Pradella M, Tonutti E, Tozzoli R, "High prevalence of celiac disease in autoimmune hepatitis detected by anti-tissue tranglutaminase autoantibodies," J Clin Lab Anal, 19(1): 6-10, 2005.

[61] Van Gerven NM, Bakker SF, de Boer YS, Witte BI, Bontkes H, van Nieuwkerk CM, Mulder CJ, Bouma G; On behalf of the Dutch AIH working group, "Seroprevalence of celiac disease in patients with autoimmune hepatitis," Eur J Gastroenterol Hepatol ePUB, Aug 2014.

[62] Sorensen HT, Thulstrup AM, Blomqvist P, Nørgaard B, Fonager $\mathrm{K}$, Ekbom A,"Risk of primary biliary liver cirrhosis in patients with coeliac disease: Danish and Swedish cohort data," Gut, 44(5): 736-8, May 1999.

[63] Lawson A, West J, Aithal GP, Logan RFA, "Autoimmune cholestatic liver disease in people with coeliac disease: a population-based study of their association," Aliment Pharmacol Ther, 21(4): 401-5, Feb 2005.

[64] Ludvigsson JF, Elfström P, Broomé U, Ekbom A, Montgomery SM, "Celiac disease and risk of liver disease: a general population-based study," Clin Gastroenterol Hepatol, 5(1): 6369.e1, Jan 2007

[65] Caprai S, Vajro P, Ventura A, Sciveres M, Maggiore G, SIGENP Study Group for Autoimmune Liver Disorders in Celiac Disease, "Autoimmune liver disease associated with celiac disease in childhood: a multicenter study," Clin Gastroenterol Hepatol, 6 (7) 803-6, July 2008

[66] Wakim-Fleming J, Pagadala MR, McCullough AJ, Lopez R, Bennett AE, Barnes DS, Carey WD, " Prevalence of celiac disease in cirrhosis and outcome of cirrhosis on a gluten free diet: A prospective study," J Hepatol, 61(3): 558-63, Sep 2014.

[67] Lindgren S, Sjöberg K, Eriksson S, "Unsuspected coeliac disease in chronic "cryptogenic" liver disease," Scand J Gastroenterol, 29(7): 661-4, July 1994.

[68] Kaukinen K, Halme L, Collin P, Färkkilä M, Mäki M, Vehmanen $\mathrm{P}$, Partanen J, Höckerstedt $\mathrm{K}$, "Celiac disease in patients with severe liver disease: gluten-free diet may reverse hepatic failure," Gastroenterology; 122(4): 881-8, April 2002. 
[69] Jacobsen MB, Fausa O, Elgjo K, Schrumpf E, "Hepatic lesions in adult coeliac disease," Scand J Gastroenterol, 25(7): 656-62, July 1990.

[70] Novacek G, Miehsler W, Wrba F, Ferenci P, Penner E, Vogelsang $\mathrm{H}$, "Prevalence and clinical importance of hypertransaminasaemia in coeliac disease," Eur J Gastroenterol Hepatol, 11(3):283-8, March1999.

[71] Elli L, Bergamini CM, Bardella MT, Schuppan D, "Transglutaminases in inflammation and fibrosis of the gastrointestinal tract and the liver," Dig Liver Dis, 41(8): 541-50, Aug 2009.

[72] Kemppainen T, Kröger H, Janatuinen E, Arnala I, Kosma VM, Pikkarainen P, Julkunen R, Jurvelin J, Alhava E, Uusitupa M, "Osteoporosis in adult patients with celiac disease," Bone, 24(3): 249-55 March 1999.

[73] Larussa T, Suraci E, Nazionale I, Leone I, Montalcini $T$, Abenavoli L, Imeneo M, Pujia A, Luzza F, "No evidence of circulating autoantibodies against osteoprotegerin in patients with celiac disease," World J Gastroenterol, 18(14): 1622-7, April 2012.

[74] Meyer D, Stavropolous S, Diamond B, Shane E, Green PH, "Osteoporosis in a north american adult population with celiac disease," Am J Gastroenterol, 96(1): 112-9, Jan 2001.

[75] Vilppula A, Kaukinen K, Luostarinen L, Krekelä I, Patrikainen H, Valve R, Luostarinen M, Laurila K, Mäki M, Collin P, "Clinical benefit of gluten-free diet in screen-detected older celiac disease patients," BMC Gastroenterol, 11: 136, Dec 2011.

[76] Krupa-Kozak U, "Pathologic bone alterations in celiac disease: etiology, epidemiology, and treatment," Nutrition, 30(1): 16-24, Jan 2014.

[77] Margoni D, Chouliaras G, Duscas G, Voskaki I, Voutsas N, Papadopoulou A, Panayiotou J, Roma E, "Bone health in children with celiac disease assessed by dual x-ray absorptiometry: effect of gluten-free diet and predictive value of serum biochemical indices," J Pediatr Gastroenterol Nutr, 54(5): 680-4, May 2012.

[78] Rastogi A, Bhadada SK, Bhansali A, Kochhar R, Santosh R, "Celiac disease: A missed cause of metabolic bone disease," Indian J Endocrinol Metab; 16(5): 780-5, Sep 2012.

[79] Basu RA, Elmer K, Babu A, Kelly CA, "Coeliac disease can still present with osteomalacia!," Rheumatol Oxf Engl, 39(3): 335-6, March 2000.

[80] Vestergaard P, Mosekilde L, "Fracture risk in patients with celiac Disease, Crohn's disease, and ulcerative colitis: a nationwide follow-up study of 16,416 patients in Denmark," Am J Epidemiol; 156(1): 1-10 July 2002

[81] Fickling WE, McFarlane XA, Bhalla AK, Robertson DA, "The clinical impact of metabolic bone disease in coeliac disease," Postgrad Med J, 77 (903): 33-6, Jan 2001.

[82] Thomason K, West J, Logan RFA, Coupland C, Holmes GKT, "Fracture experience of patients with coeliac disease: a population based survey," Gut; 52(4): 518-22, April 2003.

[83] West J, Logan RFA, Card TR, Smith C, Hubbard R, "Fracture risk in people with celiac disease: a population-based cohort study," Gastroenterology, 125(2): 429-36, Aug 2003.

[84] Ludvigsson JF, Michaelsson K, Ekbom A, Montgomery SM, "Coeliac disease and the risk of fractures - a general populationbased cohort study," Aliment Pharmacol Ther, 25(3): 273-85, Feb 2007.

[85] Olmos M, Antelo M, Vazquez H, Smecuol E, Mauriño E, Bai JC, "Systematic review and meta-analysis of observational studies on the prevalence of fractures in coeliac disease," Dig Liver Dis, 40(1): 46-53, Jan 2008.

[86] Barera G, Mora S, Brambilla P, Ricotti A, Menni L, Beccio S, Bianchi C, "Body composition in children with celiac disease and the effects of a gluten-free diet: a prospective case-control study," Am J Clin Nutr, 72(1): 71-5, July 2000.

[87] Kavak US, Yüce A, Koçak N, Demir H, Saltik IN, Gürakan F, Ozen $\mathrm{H}$, "Bone mineral density in children with untreated and treated celiac disease," J Pediatr Gastroenterol Nutr, 37(4): 434-6, Oct 2003.

[88] Rios LP, Khan A, Sultan M, McAssey K, Fouda MA, Armstrong $\mathrm{D}$, "Approach to diagnosing celiac disease in patients with low bone mineral density or fragility fractures: multidisciplinary task force report," Can Fam Physician, 59(10): 1055-1061, e441-448, Oct 2013.

[89] Luostarinen L, Himanen S-L, Luostarinen M, Collin P, Pirttilä T, "Neuromuscular and sensory disturbances in patients with well treated coeliac disease," J Neurol Neurosurg Psychiatry; 74: 490-4, Oct 2003.

[90] Cicarelli G, Della Rocca G, Amboni M, Ciacci C, Mazzacca G, Filla A, Barone P, "Clinical and neurological abnormalities in adult celiac disease," Neurol Sci, 24(5): 311-7, Dec 2003.

[91] Shen T-CD, Lebwohl B, Verma H, Kumta N, Tennyson C, Lewis S, cherl E, Swaminath A, Capiak KM, DiGiacomo D, Bosworth BP, Brannagan TH 3rd, Green PH, "Peripheral neuropathic symptoms in celiac disease and inflammatory bowel disease," $J$ Clin Neuromuscul Dis; 13(3): 137-45, March 2012.

[92] Ludvigsson JF, Olsson T, Ekbom A, Montgomery SM, "A population-based study of coeliac disease, neurodegenerative and neuroinflammatory diseases,"Aliment Pharmacol Ther; 25(11): 1317-27, Jun 2007.

[93] Freeman HJ, "Neurological disorders in adult celiac disease," Can J Gastroenterol, 22(11): 909-11, Nov 2008.

[94] Hadjivassiliou M, Grünewald RA, Kandler RH, Chattopadhyay AK, Jarratt JA, Sanders DS, Sharrack B, Wharton SB, DaviesJones GA, "Neuropathy associated with gluten sensitivity," J Neurol Neurosurg Psychiatry 2006; 77: 1262-6.

[95] Hadjivassiliou M, Duker AP, Sanders DS, "Gluten-related neurologic dysfunction," Handb Clin Neurol, 120(11): 607-19, Nov 2014.

[96] Kaplan JG, Pack D, Horoupian D, DeSouza T, Brin M, Schaumburg H, "Distal axonopathy associated with chronic gluten enteropathy: a treatable disorder," Neurology 1988; 38: 642-5.

[97] Bürk K, Farecki M-L, Lamprecht G, Roth G, Decker P, Weller M, Rammensee HG, Oertel W, "Neurological symptoms in patients with biopsy proven celiac disease," Mov Disord, 24(4): 2358-62, April 2009.

[98] Hadjivassiliou M, Grünewald R, Sharrack B, Sanders D, Lobo A, Williamson C, Woodroofe N, Wood N, Davies-Jones A, "Gluten ataxia in perspective: epidemiology, genetic susceptibility and clinical characteristics," Brain J Neurol, 126(Pt 3): 685-91, March 2003.

[99] Bürk K, Bösch S, Müller CA, Melms A, Zühlke C, Stern M, Besenthal I, Skalej M, Ruck P, Ferber S, Klockgether T, Dichgans J, "Sporadic cerebellar ataxia associated with gluten sensitivity," Brain J Neurol, 124(Pt 5): 1013-9, May 2001.

[100] Hadjivassiliou M, Aeschlimann P, Sanders DS, Mäki M, Kaukinen K, Grünewald RA, Bandmann O, Woodroofe N, Haddock G, Aeschlimann DP, "Transglutaminase 6 antibodies in the diagnosis of gluten ataxia," Neurology, 80(19): 1740-5, May 2013.

[101] Hadjivassiliou M, Davies-Jones G a. B, Sanders DS, Grünewald RA, "Dietary treatment of gluten ataxia," J Neurol Neurosurg Psychiatry; 74(9): 1221-4, Sep 2003.

[102] Gabrielli M, Cremonini F, Fiore G, Addolorato G, Padalino C, Candelli M, De Leo ME, Santarelli L, Giacovazzo M, Gasbarrini A, Pola P, Gasbarrini A,"Association between migraine and Celiac disease: results from a preliminary case-control and therapeutic study," Am J Gastroenterol, 98(3):625-9, March 2003.

[103] Zone JJ, "Skin manifestations of celiac disease," Gastroenterology, 128 (4 Suppl 1): S87-91, April 2005.

[104] Nakajima K, "Recent advances in dermatitis herpetiformi," Clin Dev Immunol, 2012:914162, July 2012.

[105] Caproni M, Bonciolini V, D’Errico A, Antiga E, Fabbri P, "Celiac disease and dermatologic manifestations: many skin clue to unfold gluten-sensitive enteropathy," Gastroenterol Res Pract, 2012: 952753, May 2012.

[106] Fasano A, "Novel therapeutic/integrative approaches for celiac disease and dermatitis herpetiformis," Clin Dev Immunol, 2012:959061, Oct 2012

[107] Ferguson R, Basu MK, Asquith P, Cooke WT, "Jejunal mucosal abnormalities in patients with recurrent aphthous ulceration," $\mathrm{Br}$ Med J, 1(6000): 11-3, Jan 1976.

[108] Abenavoli L, Proietti I, Leggio L, Ferrulli A, Vonghia L, Capizzi R, Rotoli M, Amerio PL, Gasbarrini G, Addolorato G, "Cutaneous manifestations in celiac disease," World J Gastroenterol, 12(6): 843-52 Feb 2006.

[109] Collin P, Vilska S, Heinonen PK, Hällström O, Pikkarainen P, "Infertility and coeliac disease," Gut, 39(3): 382-4, Sep 1996.

[110] Meloni GF, Dessole S, Vargiu N, Tomasi PA, Musumeci S, "The prevalence of coeliac disease in infertility," Hum Reprod Oxf Engl, 14(11): 2759-61, Nov 1999.

[111] Tiboni GM, de Vita MG, Faricelli R, Giampietro F, Liberati M, "Serological testing for celiac disease in women undergoing 
assisted reproduction techniques," Hum Reprod Oxf Engl, 21(2): 376-9, Feb 2006.

[112] Singh P, Arora A, Lal S, Strand TA, Makharia GM, "Celiac disease in women with infertility: A meta-analysis," (Under publication).

[113] Tersigni C, Castellani R, de Waure C, Fattorossi A, De Spirito M, Gasbarrini A, "Celiac disease and reproductive disorders: metaanalysis of epidemiologic associations and potential pathogenic mechanisms," Hum Reprod Update, 20(4): 582-93, July-Aug 2014.

[114] Sheiner E, Peleg R, Levy A, "Pregnancy outcome of patients with known celiac disease," Eur J Obstet Gynecol Reprod Biol, 129(1): 41-5, Nov 2006.

[115] Ludvigsson JF, Ludvigsson J, "Coeliac disease in the father affects the newborn," Gut, 49(2): 169-75, Aug 2001.
[116] Ludvigsson JF, Montgomery SM, Ekbom A, "Celiac disease and risk of adverse fetal outcome: a population-based cohort study," Gastroenterology, 129(2): 454-63, Aug 2005.

[117] Rostami K, Steegers EA, Wong WY, Braat DD, SteegersTheunissen RP, "Coeliac disease and reproductive disorders: a neglected association," Eur J Obstet Gynecol Reprod Biol, 96(2): 146-9, June 2001

[118] Makharia GK, Baba CS, Khadgawat R, Lal S, Tevatia MS, Madan $\mathrm{K}$, "Celiac disease: variations of presentations in adults," Indian $J$ Gastroenterol, 26(4): 162-6, July-Aug 2007.

[119] Smukalla S, Lebwohl B, Mears JG, Leslie LA, Green PH, "How often do hematologists consider celiac disease in iron-deficiency anemia? Results of a national survey," Clin Adv Hematol Oncol HO, 12(2): 100-5, Feb 2014. 